\title{
The consequences of restricted water accessibility on schedule-induced polydipsia
}

\author{
WILLIAM DANIEL and GLEN D. KING \\ Auburn University, Auburn, Alabama 36830
}

\begin{abstract}
Twelve naive female albino rats were assigned to three groups (four subjects per group), and each group was given access to water for one of three 20 -sec periods during the interpellet interval. Water intakes of all subjects in each group increased substantially relative to baseline conditions with nonsignificant differences in water intakes between groups. Although schedule-induced polydipsia develops under conditions of restricted water accessibility, the concept of reinforcement probability alone cannot adequately predict the relative degree of water intakes, but must be considered in relation to other potent variables.
\end{abstract}

Schedule-induced polydipsia, one of several schedule-induced behaviors, was originally observed by Falk (1961). This excessive consumption of fluids has been determined to occur when a food-restricted animal, with access to a liquid, is delivered small portions of food intermittently with interpellet intervals greater than approximately $45 \mathrm{sec}$.

Flory and Boyle (1972), studying the effects of periods $(15 \mathrm{sec})$ of water inaccessibility during the intervals of a FI 1-min food reinforcement schedule with water available on a CRF schedule, found that the quantities of fluid intake, although somewhat attenuated, were nevertheless maintained at excessive levels. Also, the reduction of intakes were generally more pronounced when the fluid was unavailable during the early segments of the interval. In their investigation, only the segments in which the subject was not allowed to drink were manipulated, and the fact that a FI schedule was employed may have initiated competing responses (drinking and barpressing) during the latter portions of the interpellet interval.

The drinking pattern during schedule-induced polydipsia, as has been repeatedly observed (e.g., Falk, 1961), is typically a postpellet phenomenon. This experiment was designed to determine if comparable levels of fluid consumption would be maintained if the drinking tube was available for only one of three equal periods $(20 \mathrm{sec})$ during the interpellet interval of a FT $65-\mathrm{sec}$ food reinforcement schedule, allowing $5 \mathrm{sec}$ after reinforcement delivery for pellet ingestion.

\section{METHOD}

\section{Subjects}

The subjects were 12 experimentally naive female albino rats (Sprague-Dawley strain), approximately 100 days old. The

This article comprised William Daniel's Master's thesis and was supported in part by Public fiealth Service Research Grants $\mathrm{MH}-08755$ and $\mathrm{MH}-12025$, and the Auburn University Research Council. Robert W. Schaeffer sponsors this paper and takes full editorial responsibility fo its contents. Requests for reprints should be submitted to Glen D. King. animals were individually housed under conditions of constant light and continuous home cage water availability. In addition to the $10045-\mathrm{mg}$ "sugarless" (cf, Christian \& Schaeffer, 1973) Noyes food pellets received during the experimental sessions, the subjects were given food supplements of Purina Laboratory Chow immediately following experimental sessions to maintain their experimental weights at $80 \%$ of their free-feeding body weights.

\section{Apparatus}

Four rat activity wheel chambers mounted on standard relay racks, and described in detail elsewhere (Schaeffer, 1966), were used. The activity wheels were braked to eliminate running and food cups were mounted within the wheels to the Plexiglas faceplate with the pellet dispenser positioned outside. Water via drinking tubes was available periodically by insertion and retraction of the tubes, accomplished by a pneumatic system through apertures in the Plexiglas faceplate. Pellet delivery, drinking tube availability, and licks at the drinking tube were recorded on an Esterline Angus digital operations recorder.

\section{Procedure}

Prior to the investigation, the 12 subjects were randomly assigned to one of three groups. Subsequent to the reduction of the animals to $80 \%$ of their ad-lib body weight, the first phase consisted of a baseline condition in which individual sessions were 108.33-min in length. During each daily session, each subjects was allowed to consume 100 pellets previously placed in the foodcup. During the first 8.33 min of each baseline session water was not available to the subjects. In the subsequent $100 \mathrm{~min}$, Group A had access to the water tube for the first $33.33 \mathrm{~min}$ of the remaining period, and Groups B and C had access to the water during the second and third 33.33-min segments, respectively.

The second phase consisted of the delivery of 100 pellets on a fixed time (FT) 65-sec schedule. An FT schedule delivers food pellets on a periodic schedule, independently of the organism's behavior. During the first $5-\mathrm{sec}$ following each pellet delivery no water was available, allowing for pellet ingestion. During the subsequent three $20-\mathrm{sec}$ segments, Group $\mathrm{A}$ had access to water during only the first $20-\mathrm{sec}$ period, Group B during only the second 20-sec period, and Group C during only the final 20-sec segment. The final phase involved the replication of the initial baseline conditions.

All of the phases continued until a stable water intake level had been maintained by each subject. The criterion for stability was met when the total of the last three session intakes minus the total of the previous three session intakes divided by the total of the last six session intakes was equal to or less than 25 . 


\section{RESULTS AND DISCUSSION}

Figure 1 presents the mean water intakes for each group during all phases of the experiment. An analysis of variance with repeated measures was conducted using the intakes for the last 6 days (i.e., the stable period) of each phase to determine if there were significant differences in water consumption between groups or phases. The results indicated a significant $(p<.01)$ difference between phases of the experiment due to the increased consumption during the experimental segment. The results did not produce a significant difference between experimental groups. An additional repeated measures analysis of variance was made using the data from the entire experimental phase. The results of this analysis indicated only a significant difference $(\mathrm{p}<.01)$ between the intakes over the days of the experimental phase, which reflects the development of the polydipsic intakes. Additional behavioral indices such as the percentage of food pellet deliveries followed by lick bursts for each animal during the last 6 days of the experimental phase, and the number of lick bursts for each animal during the last 4 days of Baseline 1 and the first 4 days of Baseline 2 yielded a nonsignificant difference as computed by separate analysis of variances for the different measures.

The results of this investigation suggest that the occurrence of polydipsic drinking is not limited to the postpellet segment of the interpellet interval, but can occur with apprently comparable vigor throughout the interval between reinforcements. Additionally, these findings provide further evidence against the early adventitious reinforcement hypothesis which was offered as a possible explanation of schedule-induced polydipsia. The adventitious association of licking and pellet delivery would predict that the highest level of fluid consumption would occur in the group having the water available at the end of the interval and the least amount in the group with water available only at the beginning of the interval. However, the results suggest that although GroupC's polydipsic level of comsumption may have been at least in part due to a fortuitous association since water was available up to the instant of pellet delivery, Group A and B's excessive intakes are contrary to the predictions generated by the adventitious reinforcement hypothesis and are apparently the result of other factors. Similar results have been reported in a recent study (Gilbert, 1974) in which the water availability period during the interpellet interval was also limited.

During the interpellet interval the probability of reinforcement is lowest immediately following pellet delivery. In addition, the frequency of competing responses with drinking (e.g., foodcup responses) is least just after pellet delivery. Therefore, as the interval between pellet deliveries lapses the probability of

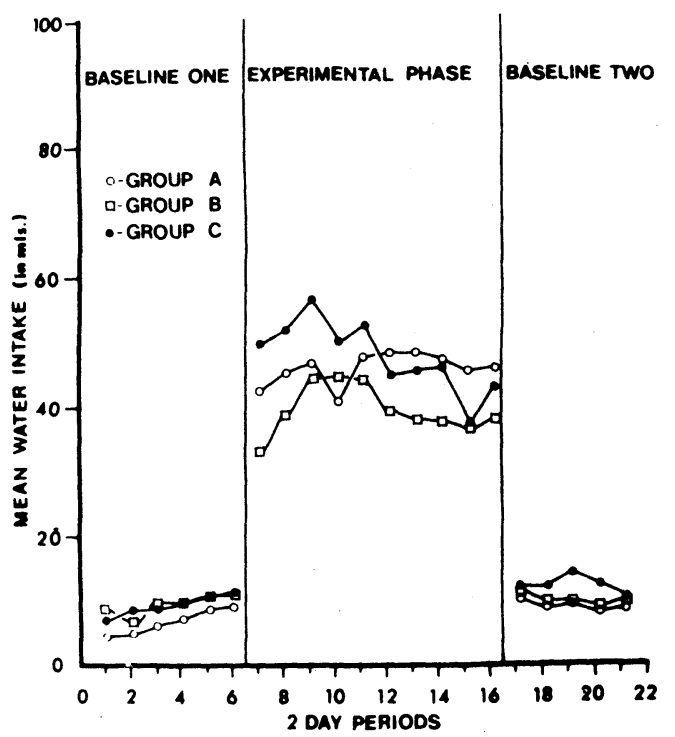

Figure 1. Mean water intakes for each group across baseline and experimental phases.

reintorcement and the frequency of drink-antagonistic responses both increase. Also, the emotional or frustration hypothesis which states that schedule-induced polydipsia is a result of the aversive aspects of a schedule of intermittent reinforcement on the food restricted animal, would predict the highest amount of water ingestion during the postpellet period since the aversive aspects of the schedule (small portions of food and long intervals between reinforcements) are most evident at this time (cf Appel, 1963). The results of this investigation cannot be accounted for by either the probability of reinforcement conception or the emotional hypothesis alone. Inspection of Figure 1 reveals that although Group A consistently had the lowest intakes during both baseline phases, the group's consumption levels during the latter part of the experimental phase exceeded the other two groups.

The relative intakes of Group A and B can be explained by the probability of reinforcement concept and the emotional hypothesis. The lower relative level of Group B's consumption, therefore, would be due to the combined effect of an increase in the probability of reinforcement an attenuation of the frustrative effects of the post-reinforcement segment of the interval. Additionally, the higher than predicted level of consumption evidenced by Group $\mathrm{C}$ can be accounted for by the fortuitous association of reinforcement with the period of water availability, since this period continued up to the time of pellet delivery.

\section{REFERENCES}

Appel, J. B. Aversive aspects of a schedule of positive reinforcement. Journal of the Experimental Analysis of Behavior, 1963, 6, 423-428.

Christian, W. P., \& Schaeffer, R. W. Note: Advisability of using 
sugar-free food pellets for schedule-induced polydipsia research. Psychological Reports, 1973, 32, 274.

Falk, J. L. Production of polydipsia in normal rats by an intermittent food schedule. Science, 1961, 133, 195-196.

Flory, R. K., \& O'Boyle, M. K. The effect of limited water availability on schedule-induced polydipsia. Physiology and Behavior, 1972, 8, 147-149.
Gilbert, R. M. Ubiquity of schedule-induced polydipsia. Journal of the Experimental Analysis of Behavior, 1974, 21, 277-284 Schaeffer, R. W. A new device for programming contingencies between drinking, running, and lever-pressing. Journal of the Experimental Analysis of Behavior, 1966, 9, 529-533.

(Received for publication December 6, 1974.) 